\title{
Thymic neuroendocrine carcinoma
}

INSERM

\section{Source}

INSERM. (1999). Orphanet: an online rare disease and orphan drug data base. Thymic neuroendocrine carcinoma. ORPHA:99869

Thymic neuroendocrine carcinoma is a type of thymic epithelial neoplasm (see this term) displaying evidence of neuroendocrine differentiation. 